\title{
BRONCHIAL CALIBRE CHANGES IN BRONCHIECTASIS ${ }^{1}$
}

\author{
By JACK GREENFIELD
}

(From the Department of Rescarch Surgery, The Ohio State Unizersity. Columbus)

(Received for publication May 3, 1940)

The modern tendency to plan for lobectomy upon a diagnosis of bronchiectasis ( 1 to 9 ) makes it mandatory that we possess as much knowledge as possible about the condition.

Since the disease is one of the bronchi and bronchioles, these structures become of marked intcrest to us. It is known that the calibre of normal bronchi increases at the end of inspiration and diminishes at the end of expiration (10) and at the end of coughing. That there is, to some extent, nervous control of these calibre changes, has also been demonstrated (11). Stimulation of the vagus constricts the bronchi and bronchioles, and stimulation of the sympathetic nerves dilates them $(12,13)$. By vagal irritation in the bronchial mucosa, the cough reflex is initiated.

Pathological investigations have shown fairly constant changes in established bronchiectasis. There is lymphocytic infiltration of all the layers of the bronchial wall. There are ulcerative changes in the mucosa and destruction of the flexible elements, namely, the muscle, cartilage and elastic fibers in the bronchial wall. There is also a transformation of the normal columnar ciliated epithelium of the mucosa to that of stratified squamous epithelium (14). As in tissues elsewhere in the body, the destroyed elastic elements are replaced by fibrous tissue (15). The mucosal changes cause loss of the cough reflex. The pathological changes in the bronchial walls produce loss of tone and stagnation of infected secretions, resulting in the gross picture of dilated or tubular bronchi and saccular bronchioles filled with purulent material. The secretions cannot be coughed up until they overflow onto normal mucosa where the cough reflex can be initiated. Consideration of the above pathological and physiological changes has led to the conclusion that they are irreversible and that only removal of the involved lobes would affect a cure $(2,15)$.

The introduction of iodized oil (lipiodol, Ia-

1 This work was aided by a grant from the Comly Fund for Research of the Ohio State University. fay) by Forestier and Sicard (17) and the simple method of instilling it into the bronchial tree, originated by Singer (18), made it possible to outline the air passages with ease. Taking advantage of this method, Heinbecker (10), in 1927, studice the calibre changes in the bronchi of humans and animals during normal respiration. He found, as mentioned above, that the bronchi and bronchioles widened at the end of inspiration and varrowed at the end of expiration. These changes occurred even when the lungs were removed from the influence of the nervous system. He explained the narrowing and widening on a passive basis, as resultants of linear and radial tractions, the character and relative degrees of which are determined by the manner of enlargement of the thoracic cavity during respiration.

It occurred to the author that the bronchi of individuals with bronchiectasis could be similarly investigated. One normal individual and four patients with established bronchiectasis, thus studdied, are presented in this report.

\section{METHOD}

After instillation of the iodized oil by the Singer method, the bronchial tree in the affected lobe was examined under the fluoroscope for calibre changes on deep inspiration and deep expiration. For permanent records, $\mathrm{x}$-ray films were taken while the breath was being held at these extremes of respiration. All radiographs were taken at a constant distance, three feet, and all exposures made very quickly to avoid the effects of motion in the films. Suitable markers were placed on the plates to identify the phases of respiration with which they were associated.

\section{RESULTS}

For the purposes of comparison with the findings in the patients with bronchiectasis, normal individuals were first studied in the above manner. One such normal subject is presented (Figure 1). It can be seen in his bronchograms that the bronchi and bronchioles are largest at deep inspiration and smallest at deep expiration. In 


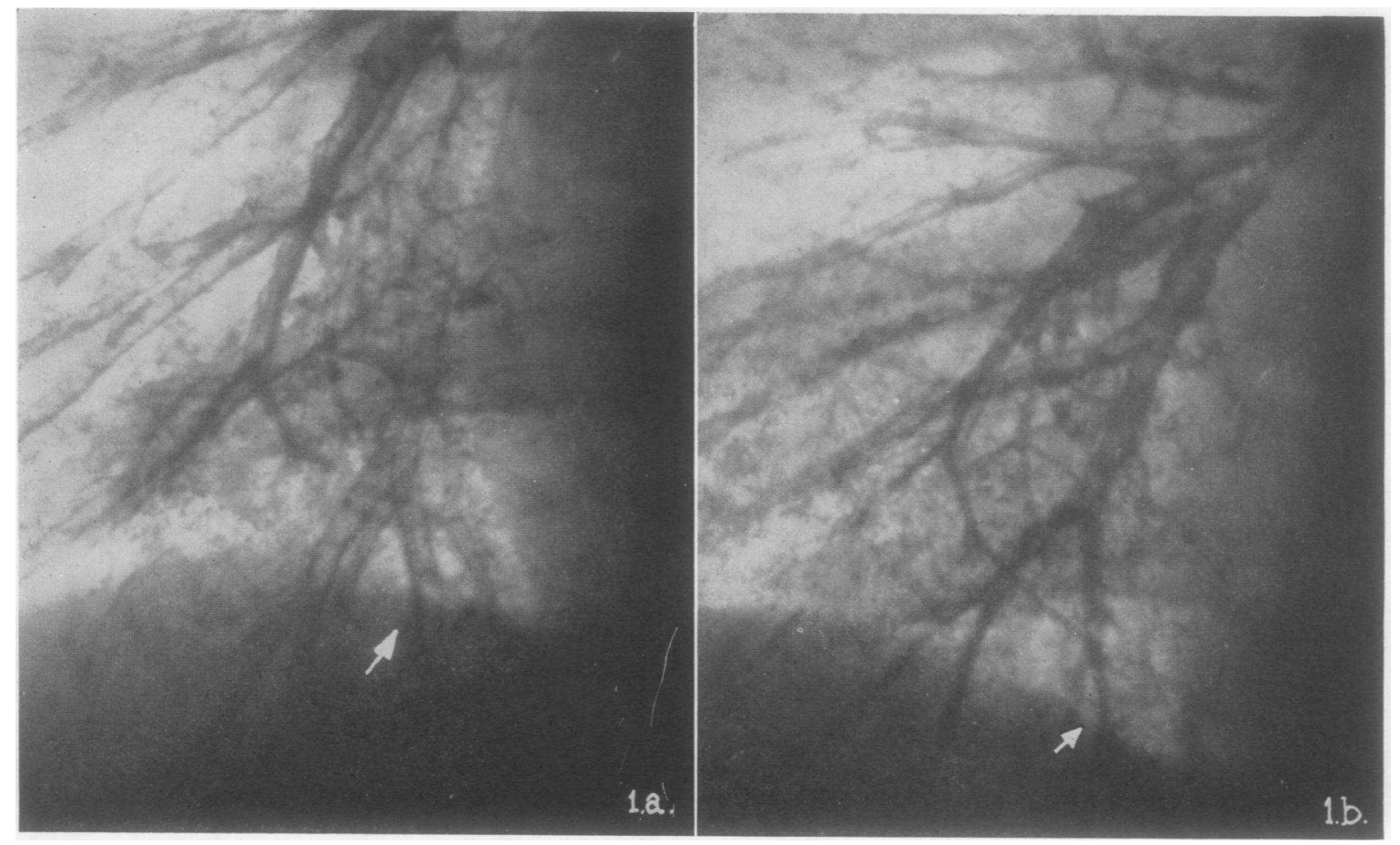

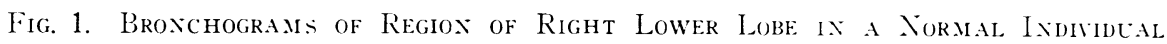

No. 1-a taken at the end of deep inspiration. Radiograph No. 1-b taken at the end of deep expiration. All the bronchi and bronchioles in 1-a are decidedly larger. Arrow points to the same bronchus in both. Note that the indicated bronchus at expiration is about one-third the diameter of that on inspiration.

order for this to occur, the elastic elements in the bronchial walls must be intact.

Cases with "wet" bronchiectasis were then studied in a similar manner to determine the response of the diseased bronchi and bronchioles. Short histories with the results of the investigation in two such cases follow:

E. G. This 19-year-old white boy was first seen in the Thoracic Surgery Clinic at the University Hospital in October, 1939. Fifteen years prior he had had 'pneumonia' and since then he had had a chronic cough productive of large amounts of foul, purulent sputum. He had consumed a large amount of cough syrup during these years, without relief. Lpon examination, there were heard numerous coarse râles in the left lower chest. Clubbing of the fingers and toes was present. The breath was foul. The sputum was negative for acid-fast organisms. Bronchograms after lipiodolization showed tubular and saccular bronchiectasis in the region of the left lower lobe. When studied according to the method of Heinbecker, the affected bronchi did not change in calibre at the inspiratory or expiratory extremes of respiration (Figure 2). The normal bronchi above the affected region, however, did respond in the physiological manner. This patient is being prepared for lobectomy by repeated postural drainage and therapeutic lipiodolizations.

R. A. This 19-year-old white girl was first seen in the Thoracic Surgery Clinic at the University Hospital in November, 1939. She had had a chronic cough, paoductive of large amounts of purulent sputum since childhood. Recently she had begun to have occasional attacks of hemoptysis and, therefore, had been hospitalized in a tuberculosis sanatorium. Repeated examinations of the sputum were negative for acid-fast bacilli. Upon examination in the clinic there were found coarse moist râles over both lower lobes, poor motion of the chest upon respiration, clubbing of the fingers and toes, and signs of weight loss. Fluoroscopic and x-ray examination, after injection of the bronchial tree with lipiodol by the Singer method, showed tubular and saccular bronchiectasis in both lower lobes. There was no change in the calibre of the bronchi or bronchioles in either lower lobe upon deep inspiration or deep expiration. The bronchogram of the right lower lobe is shown in Figure 3 . Since the patient is sensitive to iodine, she is being prepared for bilateral lower lobectomy by postural drainage. If postural drainage does not rid her of the infected secretions, $\mathrm{x}$-ray therapy will be used to 'dry' her bronchiectasis.

From the above it became apparent that these diseased bronchi are incapable of the normal calibre changes. Some still cling to the belief that 


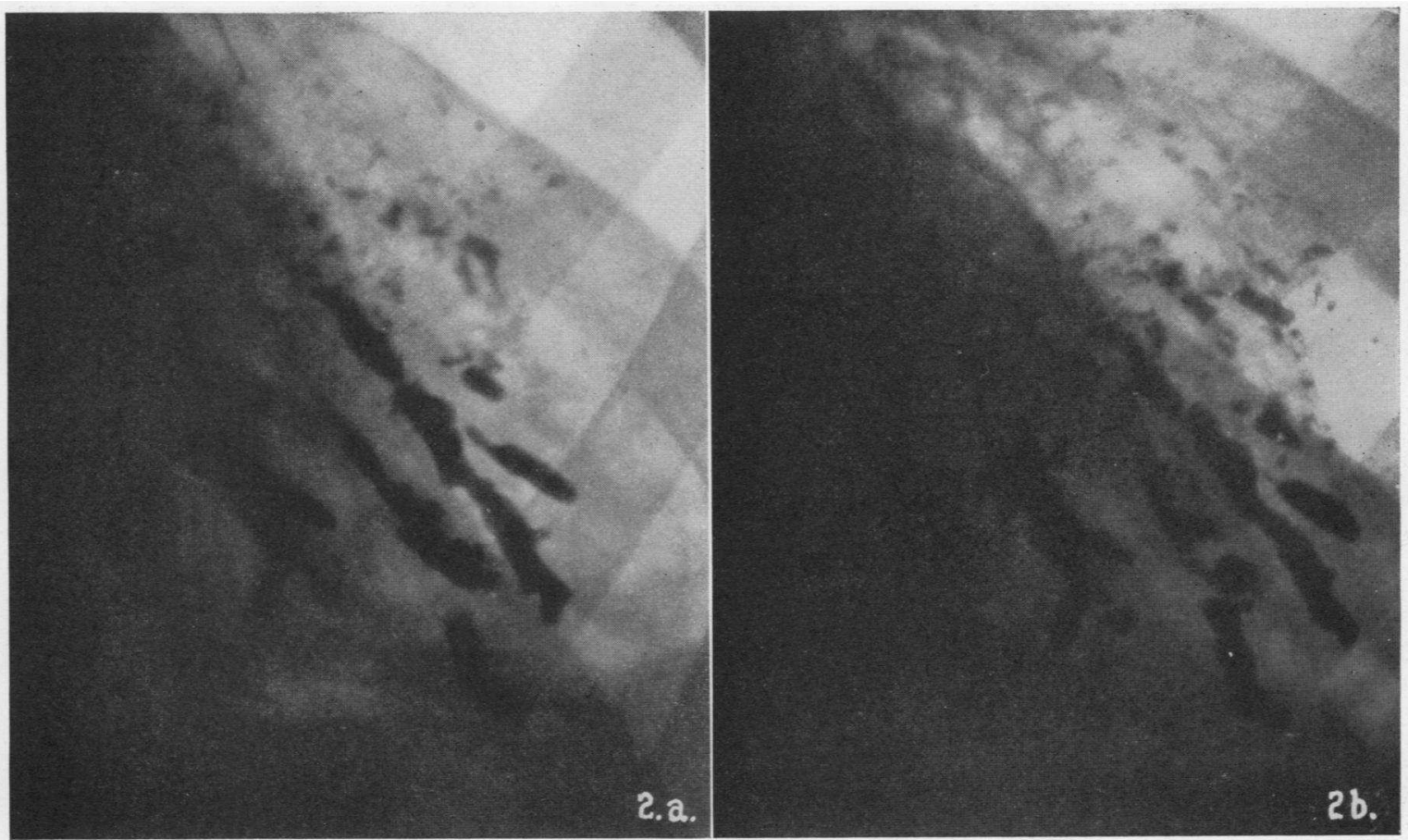

Fig. 2. Bronchograms of Region of the Left Lower Lobe in a Case of Established “Wet" Tlbllar and SaCcllar Broichiectasis

No. 2-a taken at the end of deep inspiration and No. 2-b at the end of deep expiration. Note absence of change in calibre of bronchi and bronchioles at the two extremes of respiration.

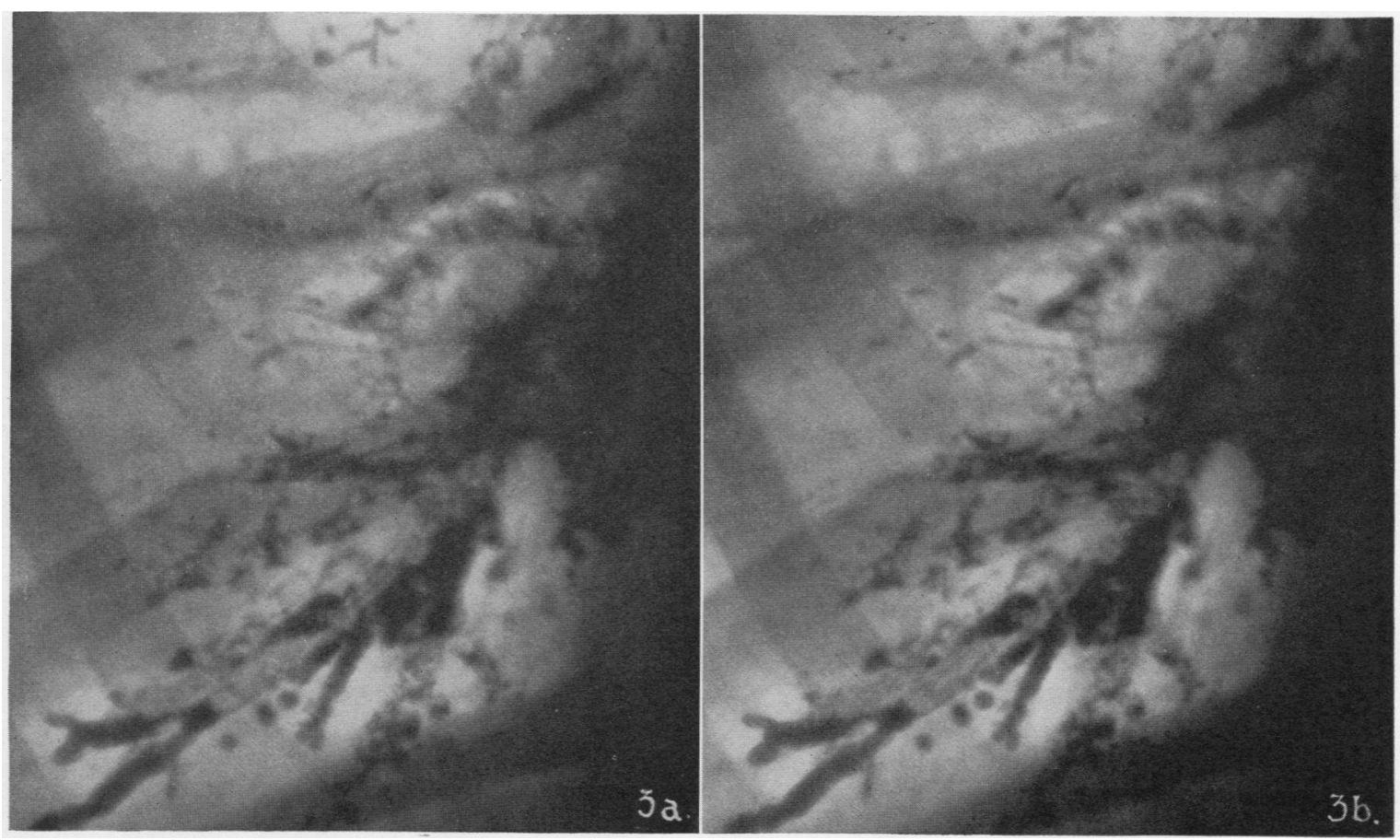

Fig. 3. Bronchograms of Region of the Right Lower lobe in a Case of Bilateral " Wet" Tubular and Saccular Bronchiectasis

No. 3-a taken at deep inspiration and No. 3-b at deep expiration. There is no change in the calibre of the affected bronchi at these phases of respiration. 


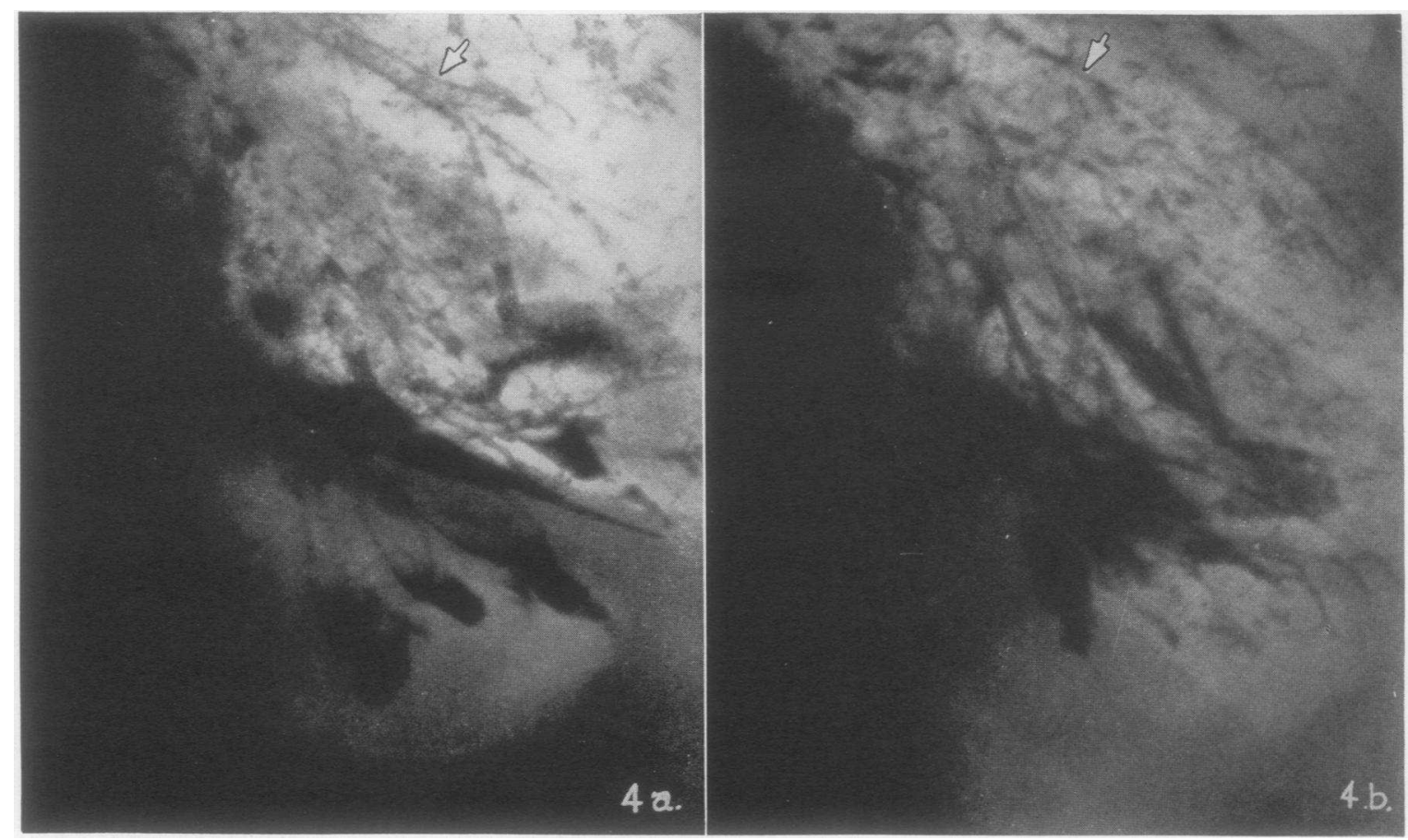

Fig. 4. Bronchogram of Left Lower Lobe in a Case of "Dry" Bronchifctasis

No. 4-a taken at deep inspiration and No. 4-b at deep expiration. There is no change in calibre of the affected bronchi at the extremes of respiration, but the normal bronchi in the upper part of the lobe do show the expected changes (arrows).

by making cases of bronchiectasis symptom-free, cure is effected. To determine whether such is the case, individuals made " dry" by conservative measures were studied in the manner described for those with "wet" bronchiectasis. Two of these, with results, are presented:

I. C. This 26-year-old white man was seen on the Research Surgical Service at the Lniversity Hospital in May, 1939. He had a history of cough productive of large amounts of purulent sputum, of twenty-two years' duration. He could not remember a predisposing illness, but had been bothered with chronic sinusitis all his life. Examination revealed coarse, moist râles in the right lower lobe. The sputum contained no acid-fast bacilli. Bronchograms showed tubular and saccular bronchiectasis in the lower part of the left lower lobe. With daily postural drainage and bimonthly therapeutic use of lipiodol he became "dry" in three months. Five months after becoming dry he was studied according to the method of Heinbecker. Although he was symptom-free, there was no morphological improvement and the dilated bronchi and bronchioles did not change in calibre at the extremes of respiration. However, the unaffected bronchi in the upper part of the lobe responded in the normal manner (Figure 4). This patient is to have a left lower lobectomy when his sinusitis is corrected.
H. M. This 24-year-old white boy was made "dry" by treatment and had a right lower lobectomy for bronchiectasis in 1938. On subsequent examination after instillation of lipiodol, it was found that the bronchi of the right middle lobe, which had expanded to fill the residual space, were also ectatic. He was, nevertheless. symptom-free. Evidently, because of inadecuate visualization of the entire bronchial tree, before operation, this involvement was not recognized. When studied by the Heinbecker method there was no change in the calibre of the affected bronchi or bronchioles (Figure 5 ). $\mathrm{Hc}$ is at present being treated by means of lipiodol every two months and precautions are taken to prevent upper respiratory infection. He will eventua!ly need to have a lobectomy of the right middle lobe.

Apparently, there is no improvement in the morphological appearance or in the physiological reaction of the affected bronchi when the bronchiectasis is made " dry" and the patient symptomfree.

\section{DISCLSSION}

The conclusion arrived at by Biermer (14) and Warner (16) from their respective pathological and clinical observations was that the changes exhibited in bronchiectasis are irreversible when managed by conservative measures. Their con- 

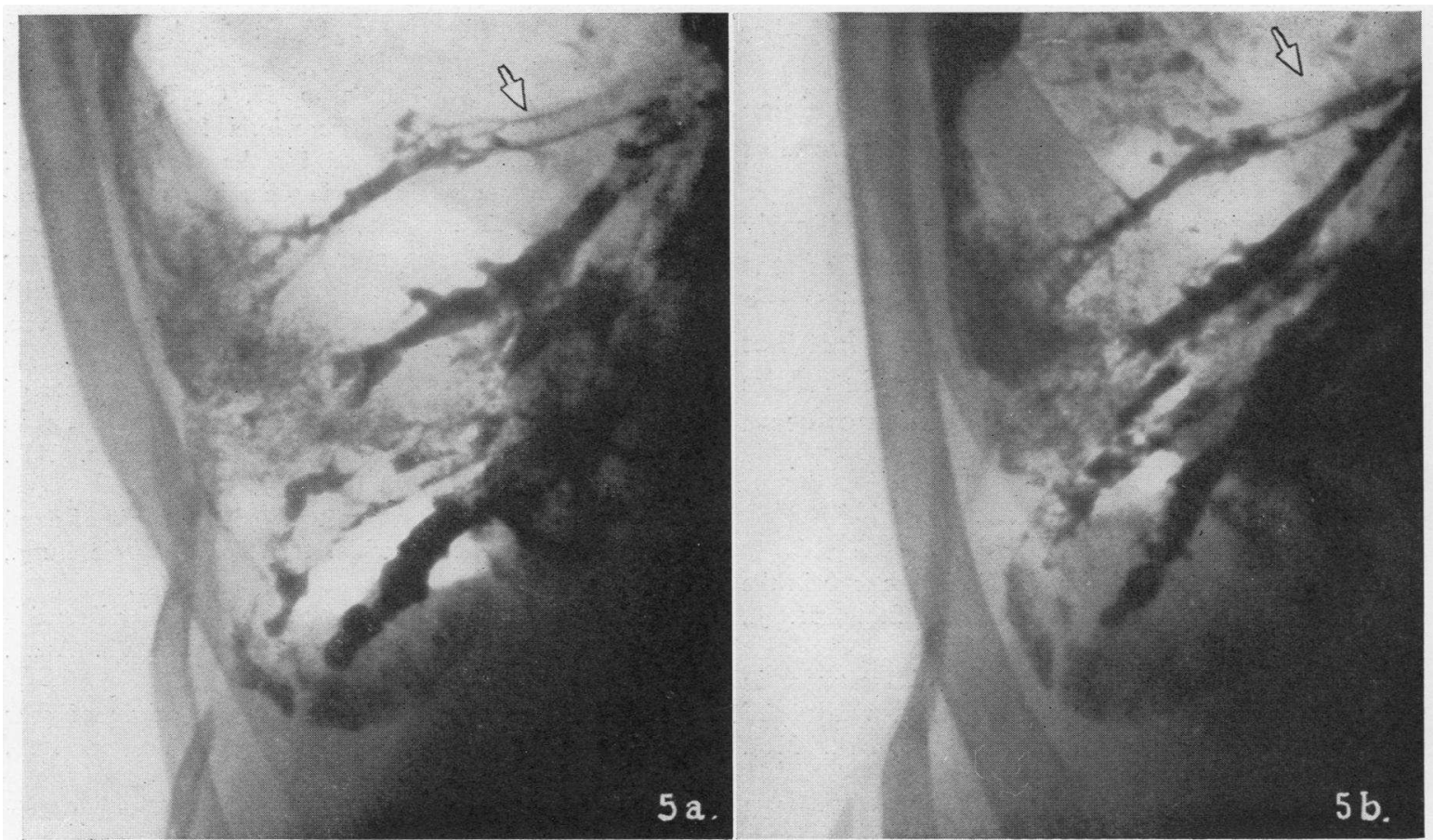

Fig. 5. Bronchogram of Right Lower Lobe in a Case of “Dry" Bronchiectasis in Whom the Right LOWer Lobe Has Been Removed

No. 5-a taken at deep inspiration and 5-b at deep expiration. No change in the calibre of the affected bronchi can be seen. Note, however, the change in calibre in the normal bronchus (arrow).

tention is further borne out by these studies. The persistent tubular and saccular ectasia of the bronchi, as well as their inability to respond normally at the extremes of respiration in the cases of bronchiectasis made "dry" by treatment, is clear evidence that the pathologgy remains unchanged when symptomatic improvement is obtained.

It is believed that no matter what initiates the series of events leading to the final picture of bronchiectasis, there must be an infection of the bronchial walls, a bronchitis, preceding the final destructive process. It may be that there is a phase, before destruction of the flexible tissues becomes marked, where the condition is still reversible. Ochsner (19) reported four cases in which he obtained morphological as well as symptomatic cure, and Berck and Harris (20) reported some cases in which they not only obtained symptomatic improvement, but shrinkage of the dilated bronchi. The former used postural drainage and repeated treatment with lipiodol, and the latter used Roentgen irradiation as the method of management.
It has not been the good fortune of the author to obtain such " early" cases of bronchiectasis for study. It is possible that the ectatic bronchi and bronchioles in such cases might become narrower in calibre upon deep expiration and wider upon deep inspiration. By this method of study it would be possible to select certain cases for conservative management instead of preparing them for lobectomy as is now customary in wellestablished cases.

\section{CONCLUSIONS}

1. The calibre changes in the bronchi of normal individuals, and in cases of "wet" and "dry" bronchiectasis were studied by the method of Heinbecker.

2. Whereas the unaffected bronchi were found to be dilated upon inspiration and constricted upon expiration, the affected bronchi in the "wet" cases did not change in calibre. Particularly notable was the lack of constriction on deep expiration.

3. The affected bronchi and bronchioles in the case of bronchiectasis made " dry" retained their 
ectatic state and likewise did not change in calibre at the extremes of respiration.

4. These studies lend evidence to the opinion that well-established bronchiectasis is irreversible and that surgery is indicated for cure.

5. It is suggested that by this method early cases, in which the marked destruction of the flexible elements of the bronchial walls has not yet occurred, might be recognized by the fact that the bronchi remain capable of changing in calibre at the extremes of respiration. Such cases could be treated conservatively instead of surgically.

\section{BIBLIOGRAPHY}

1. Curtis, G. M., and Knierim, H. G., Lobectomy in the treatment of bronchiectasis. Ohio State M. J., 1939, 35, 1286.

2. Edwards, A. T., Modern principles of treatment in bronchiectasis based upon 199 cases treated by lobectomy or total pneumonectomy. Brit. Med. J., 1939, 1, 809.

3. Lilienthal, H., Thoracic Surgery. The Surgical Treatment of Thoracic Disease. W. B. Saunders Co., Philadelphia, 1925, 2, p. 134.

4. Heuer, G. J., The development of lobectomy and pneumonectomy in man. J. Thoracic Surg., 1934, 3, 560 .

5. Brunn, H. B., Surgical principles underlying one stage lobectomy. Arch. Surg., 1929, 18, 490.

6. Churchill, E. D., Lobectomy and pneumonectomy in bronchiectasis and cystic disease. J. Thoracic Surg., 1937, 6, 286.

7. Harrington, S. W., One stage lobectomy for bronchiectasis of the right lower lobe. Proc. Staff Meet., Mayo Clin., 1936, 11, 209.

8. Shenstone, N. S., and Janes, R. M., Experience in pulmonary lobectomy. Canad. M. A. J., 1932, 27, 138.

9. Curtis, G. M., and Knierim, H. G., Bronchiectasis. Timely Tidings on Tuberculosis, 1939, 5, 3.

10. Heinbecker, P., A method for the demonstration of calibre changes in the bronchi in normal respiration. J. Clin. Invest., 1927, 41, 459.

11. Weber, E., Studies over det respiratorische nerve system hos Fluisoeldyreue. Kopenhagen, 1910. Cited from L. R. Muller, Die Lebensnerven. Zweite Auflage, Springer, Berlin, 1924, p. 222.

12. Mount, H. T. R., Experimental study of effects of stimulation and section of vagal innervation to bronchi and their possible relation to asthma. Am. J. M. Sc., 1929, 177, 697.

13. Nicholson, W. F., Observations of the effect of amyl nitrite on the bronchial tree. J. Thoracic Surg., 1939, 9, 194.

14. Biermer, W., Zur Theorie und Anatomie der Bronchienerweiterung. Virchow's Arch. f. Path. Anat., $1860,19,94,241$.

15. Olch, I. Y., and Ballon, H. C., The origin of scar tissue in healing of the lung. Arch. Surg., 1929, 19, 1595.

16. Warner, W. P., Factors causing bronchiectasis; their clinical application to diagnosis and treatment. J. A. M. A., 1935, 105, 1666.

17. Forestier, J., and Sicard, J. A., Radiological exploration with iodized oil. Brit. J. Radiol., 1926, 31, 239.

18. Singer, J. J., Simple method of introducing iodized oil into the lungs. J. A. M. A., 1926, 87, 1298.

19. Ochsner, A., Bronchiectasis. Am. J. M. Sc., 1930, 179, 388.

20. Berck, M., and Harris, W., Roentgen therapy for bronchiectasis. J. A. M. A., 1937, 108, 517.

21. Brunings, W., Direct laryngoscopy, bronchoscopy, and oesophagoscopy. Tr. and ed. by W. G. Howarth. Baillière, London, 1912, p. 138. 